\title{
AGROECOLOGIA NO ENSINO DA GEOGRAFIA: RELATO... ESTÁGIO SUPERVISIONADO, PRÁTICAS ${ }^{1}$
}

\author{
Thales Ravel Hetka Okonoski ${ }^{2}$ \\ Almir Nabozny ${ }^{3}$
}

\begin{abstract}
Resumo
Este trabalho visa apresentar os procedimentos e os respectivos debates de práticas docentes exercidas no âmbito dos estágios supervisionados no curso de Licenciatura em Geografia da Universidade Estadual do Centro-Oeste (UNICENTRO, Campus de Irati-PR). As reflexões estão pautadas pela discussão do tema da agroecologia como uma possibilidade de debate no campo da educação geográfica. No texto debatemos aspectos conceituais da agroecologia, bem como suas possíveis relações com temas do repertório geográfico. Apresentamos dois relatos de práticas pedagógicas vinculadas aos estágios de docência. Como discussões, destacamos a imbricação entre a práxis do professor supervisor da universidade e do docente em formação; apontamos algumas dificuldades vivenciadas no cotidiano das práticas pedagógicas na escola, tais como, transposição didática, horários e recursos para as aulas. Também, destacamos as potencialidades para o debate das questões agroecológicas no ensino de Geografia numa perspectiva de trânsito, assim como, traçamos algumas críticas ao exclusivismo do temário transversal proposto pelos Parâmetros Curriculares Nacionais (PCN'S).
\end{abstract}

Palavras-chave: Ensino de Geografia. Estágio de Docência. Agroecologia.

\begin{abstract}
The purpose of this study is to present the proceedings and the debates concerning the teaching practice trainings in the Course of Geography at the Universidade Estadual do Centro-Oeste (UNICENTRO, Campus of Irati - PR). Reflexions about the object are guided by a discussion about the agroecology theme as a possibility of the discussion in the field of geographic education. This text discusses conceptual aspects of agroecology, as well as these possible relations with themes of geographic studies. This article presents two reports of pedagogical practices linked to the stages of teaching. The discussions featured are: the link between the college supervisor professor praxis and the student praxis; the appointment about some difficulties founded in the routine of pedagogical practices in the school, such as didactical transposition, time and tools available to the classes. We also feature the potentiality to the discussions of the questions about the theme of agroecology in Geography studies in a prospect of moving, as well as, we made some critics about the exclusivity of transversal themes proposed by the National Curricular Models (Parâmetros Curriculares Nacionais PCN's).
\end{abstract}

Keywords: Geography Teaching. Teaching Practice. Agroecology.

\footnotetext{
1 Esse texto é originário das práticas de estágios de docência em Geografia, realizados no curso de Licenciatura em Geografia da Universidade Estadual do Centro-Oeste (UNICENTRO). Campus de Irati - PR

2 Mestrando em Gestão do Território na Universidade Estadual de Ponta Grossa - PR (UEPG). Email: geo_ravel@yahoo.com.br

3 Doutorando em Geografia na Universidade Federal do Rio Grande do Sul (UFRGS). Email: almirnabozny@ yahoo.com.br
} 


\section{INTRODUÇÃO}

A agroecologia constitui-se em um campo de conhecimento surgido da união de conhecimentos científicos advindos, principalmente, de estudos de agronomia, ecologia e de conhecimentos práticos obtidos por agricultores (valorização da racionalidade tradicional), através de anos de experiências, em busca de novas técnicas de produção agrícola ambientalmente mais harmoniosas.

Dessa maneira, a agroecologia apresenta-se como uma possibilidade de mudança na construção social da realidade do agricultor que a pratica, pois além de modificar a forma de produção, ela dinamiza os contatos entre agricultores para troca de experiências, bem como altera a forma de o agricultor se relacionar com o ambiente em que vive, tanto em seu contexto físico como também em seu aspecto social, constituindo-se, portanto, em uma relação dialógica, ou seja, uma ligação totalizante. Dessa forma, no texto às vezes iremos inferirmos ao ensino de Geografia, o debate agroecológico, enquanto temática relacionada a debates culturais, sociais, econômicos, entre outras qualificações. No entanto essas qualificações visam apontar para complexidade do termo, uma vez que a ideia de ambiente que partilhamos "indica a compreensão do ser na relação com seu entorno" (SUERTEGARAY, 2004.p.113 - sem grifos no original), não havendo dicotomitizações entre os predicados que assinalamos.

Sendo assim, a agroecologia apresenta-se passível de uma análise dentro do campo da Geografia, pois é um potencial de transformação de toda uma forma de viver, de produção e de relação com o espaço geográfico, no qual os agricultores são grandes agentes das dinâmicas espaço-temporais. Partindo dessa lógica, buscou-se debater as questões ambientais e agrícolas desses processos com os educandos do Ensino Fundamental e Médio, durante as práticas de docência do estágio supervisionado do curso de Geografia, sendo que um dos estágios foi desenvolvido no Ensino Fundamental, mais precisamente com os alunos da $8^{\mathrm{a}}$ série A, e outro no Ensino Médio, com os alunos da $1^{\text {a }}$ série A, ambos do Colégio Estadual Duque de Caxias, de São Mateus do Sul - PR.

Nesses estágios, foram exploradas as relações da Geografia com os processos locais, desenvolvidos no espaço conhecido pelos educandos, tendo sido trabalhado o tema agroecologia em relação à agricultura camponesa e à agricultura convencional. Para tanto, foram tomados como pressupostos de partida os temas estabelecidos pelos Parâmetros Curriculares Nacionais (PCN's), em que a Geografia, dentro de suas práticas de ensino, deve 
abranger a relação do lugar onde preexistem acontecimentos referentes à "realidade" dos educandos com outras esferas de análises mais amplas, como a regional, a nacional e a global, estando implícito a necessidade de trabalhar-se com jogos de diferentes escalas geográficas e sensíveis. Outro aspecto trabalhado na prática educativa foi o debate da agroecologia como possível demanda local, em que é plausível desdobrar os chamados temas transversais (dentro de um olhar crítico dos mesmos), e entre esses uma correlação entre ambiente, educação e saúde.

Com relação aos aspectos de elaboração e a metodologia de apresentação desse texto cabe frisarmos um esclarecimento. Como o fez Sahr e Sahr (2009) poderíamos grafar o texto em duas fontes, demarcando uma reflexão ora mais empírica, ora mais conceitual.

Contudo, trata-se de um texto originário da prática de estágios de docência vinculados a um curso de Licenciatura em Geografia. Uma narrativa reflexiva escrito à quatro mãos. Estando imbricadas duas práticas pedagógicas, as quais por conseguinte estruturam os argumentos. Nos quais os conceitos estão plenamente eivados pelas práticas. Num primeiro aspecto temos o encontro do professor orientador de estágio (docente também em formação), refletindo com seu educando (docente em formação). Assim, há uma orientação reflexiva da/para a experiência docente a ser exercida. Por outro lado num segundo momento (e propositalmente) escrevemos o texto num tom mais de relato. Destacando a prática docente no estágio, refletindo sobre a mesma num encontro com o professor orientador. Re-orientando as duas práticas para um futuro. Ou seja, diálogos, em que ambos aprendem.

Dessa forma o artigo busca no encontro com possíveis leitores, provocá-los sobre dois aspectos. Primeiro é o de suscitar reflexões entorno da agroecologia como uma temática complexa e interessante de ser problematizada no âmbito do ensino de Geografia 4 .

Em segundo lugar (sem hierarquizar) fazer algumas insinuações entorno dos estágios em cursos de licenciaturas, sinalizando para superação da perspectiva do professor da universidade que efetua uma avaliação crítica da prática pedagógica do estagiário, dentro de critérios pedagógicos, didáticos, metodológicos (formais) caracterizando-se numa relação de formatação do futuro professor. Do contrário nossa perspectiva visa sinalizar para um encontro dialógico (diálogo) e dialético (de transformação de ambos). Caracterizando uma ideia efetiva de formação, de processo, de movimentos, de criação.

4 Ainda que sejam incipientes, algumas experiências têm sido tracejadas nesse caminho. Ver por exemplo, Ferreira et al (2009). 


\section{UMA TEMÁTICA EM TRÂNSITO: A AGROECOLOGIA COMO UMA POSSIBILIDADE NO ENSINO DE GEOGRAFIA}

Dentro do processo de desenvolvimento das ciências, na busca por respostas a temas problematizados em diferentes contextos, como sociais, ambientais, econômicos, culturais, entre outros, a Geografia surgiu, inicialmente, trabalhada por filósofos na Grécia Antiga, que, mesmo sem uma organização em torno de um objeto comum, já realizavam observações do espaço, caracterizadas hoje como análises geográficas ${ }^{5}$. Para ficarmos somente no campo da ciência, uma vez que alguns autores, tais como, Lowenthal (1982) sabiamente nos chamam atenção para o conhecimento geográfico eivado nas práticas e reflexões do cotidiano, por pessoas que não são intituladas de geógrafas e geógrafos.

Assim, os pressupostos da ciência, pautados em um pensamento positivista, encaminharam a Geografia para um estudo descritivo do meio, passando por uma percepção das diferentes relações, como sociedade e meio, até interpretações de espaços cada vez mais complexos, envolvidos em processos dinâmicos, integrantes e excludentes, remetendo à ideia de um meio técnico/científico/informacional (SANTOS, 1996).

O estudo da Geografia, ao longo dos tempos, teve influências de inúmeras correntes de pensamentos que, de acordo com seus princípios, direcionaram as pesquisas geográficas. Sendo essas inter-relações fundamentadas sobretudo na modernidade (GOMES,1996). Essas correntes, em variadas discussões, receberam críticas relacionadas aos seus objetos de estudo, métodos e teorias. Entretanto, é inegável a importância delas para a elaboração da forma de pesquisar e ensinar Geografia nos dias de hoje. A evolução desse pensamento geográfico, passando por correntes como a naturalista, determinista, possibilista, quantitativa e crítica, criou conceitos de análise que são utilizados para diferentes percepções do espaço geográfico, tais como território, lugar, paisagem, região (MORAES, 2003).

No Brasil, esse processo teve influência possibilista e positivista, dentro dos padrões instaurados pela escola francesa, porém o sistema educacional brasileiro atual contém resquícios do padrão tradicional de ensino, no qual as práticas de ensino separam determinados assuntos em disciplinas, sendo difícil ao educando perceber que para o entendimento de inúmeras realidades torna-se necessária uma análise integradora dessas disciplinas. Além disso, o processo de ensino/aprendizagem pautava-se pela aquisição dos

5 Para maiores aprofundamentos, consultar: PEREIRA, M. F. R. A Geografia no pensamento filosófico. In: MERCATOR - Revista de Geografia da UFC. ano 05, número 10, p.31-37. 2006. 
conceitos repassados pelo professor, sem que o educando fosse incentivado à reflexão sobre os assuntos (PCN's, 2001).

Essa lógica somente começou a mudar com a "abertura política" do país e com a inserção do pensamento crítico, que favoreceu a elaboração de livros didáticos mais voltados às relações sociais e ambientais e às suas respectivas consequências para o meio, e com a formação de professores dispostos a despertar um senso crítico nos alunos, formando cidadãos mais conscientes e integrados ao meio em que vivem (CAVALCANTI, 2002).

De acordo com as propostas criadas pelo Governo Federal, estruturadas como Parâmetros Curriculares Nacionais (PCN's, 2001), o espaço geográfico deve ser lido e compreendido pelos educandos como uma construção humana que se desenvolveu sobre uma superfície terrestre, que é também um meio biofísico, ou seja, um meio constituído como a primeira natureza. Entretanto, para que essa construção seja realizada de forma equilibrada, de maneira a evitar futuras consequências nocivas a toda humanidade, os processos de construção desse espaço e seus desdobramentos devem ser conhecidos pelos educandos, bem como os processos naturais e os decursos históricos que conduziram à formação da sociedade em que vivemos e à modificação do espaço natural. Além disso, os alunos devem compreender as razões sociais, econômicas e políticas envolvidas nesse contexto.

Cavalcanti (2002) declara:

O objeto do estudo geográfico na escola é, pois, o espaço geográfico entendido como um espaço social, concreto, em movimento. Um estudo do espaço assim concebido requer uma análise da sociedade e da natureza, e da dinâmica resultante da relação entre ambas. (CAVALCANTI, 2002. p. 13)

O ensino da Geografia, por sua vez, objetiva, de forma geral, construir com os educandos compreensões do espaço geográfico dentro das relações que o modificam e o dinamizam constantemente. Para que os educandos tenham um aprendizado significante dessas dinâmicas espaciais em geral torna-se necessário relacionar o ensino com a construção social da realidade vivida pelos educandos (o sentido de construção social da realidade advêm de BERGER e LUCKMANN, 1985), o que tornará possível, após o entendimento dos processos socioeconômicos, ambientais e culturais existentes no local. Juntamente com a extrapolação desses processos para apreensões espaciais mais amplas, relacionando-os a ideias como a globalização, dinâmicas econômicas complexas, entre outros temas inclusos no processo de ensino/aprendizagem do sistema educacional brasileiro. Ainda mantendo como referência a perspectiva ancorada nos Parâmetros Curriculares Nacionais (PCN's, 2001), nota- 
se uma clara atenção para o debate da escala geográfica de abrangência e inteligibilidade dos fenômenos espaciais.

Dessa maneira, através da relação da Geografia com os processos locais relativos ao espaço conhecido pelos alunos, a agroecologia relacionada à agricultura camponesa e à agricultura convencional, seguindo a ideia de transversalidade proposta pelos Parâmetros Curriculares Nacionais (PCN’s), pode ser - e é - trabalhada dentro da educação geográfica do Ensino Fundamental e Médio nas escolas de São Mateus do Sul-PR, pois esse tema está fortemente ligado à realidade agrícola do município.

Apontamos a transversalidade enquanto uma sinalização efetivada no documento oficial - PCN's. No entanto não somos partidários da ideia da estipulação de temas específicos (saúde, sexualidade, meio ambiente, pluriculturalismo, ética e trabalho, por exemplo), os quais seriam (únicos) merecedores do tratamento interdisciplinar, envolvendo a interação de disciplinas nas conjunções de suas análises. Chamamos de importante sinalização no sentido que traz no seu bojo uma crítica a racionalidade fragmentária. Tornando-se necessário que os educandos compreendam a importância das diversas relações - como as sociais, econômicas, ambientais e culturais - existentes no lugar em que vivem, dentro dos contextos locais, regionais e globais, e percebam, assim, que todos fazem parte dessas relações e influenciam as dinâmicas decorrentes delas, ora com mais, ora com menos potencialidade de ação.

O ensino da Geografia no âmbito escolar sumariamente já remete-se a um diálogo com outras áreas do conhecimento. Vide, por exemplo, as problemáticas ambientais. Mas também é preciso traçarmos uma crítica fundamentada no objeto da educação. A qual para nós está fundamentado em educandos (os mais diversos, pobres, ricos, ...), educadores, salas de aula, horários, conflitos sociais, entre outros aspectos, constituintes de um objeto complexo e multidimensional. Em que as teorias (aprendizagem, metodologias...) são representações desse objeto e ao mesmo tempo que passam a serem mais um elemento de composição do mesmo. Dessa forma a interdisciplinariedade suscitada pela ideia de tema transversal, na atual conjuntura do objeto da educação só se viabiliza em projetos e em intervenções pontuais (em tempo e espaço).

Assim, é preciso pensarmos em táticas de contemplação da necessidade de pensarmos de forma complexa (MORIN, 1996) ou de tratamento adequado daquilo Latour (1994) denomina de híbridos, dentro das condições totalizantes que o objeto da educação nos projeta. Em que acenamos para algo menos ambicioso que a interdisciplinariedade, a ideia singela de trânsito, num sentido que o educador transite e dialogue com outros conhecimentos (racional, 
tradicional) e outras perspectivas (disciplinas), acrecidos daquilo que Santos (2008) denomina de emoção. Constituindo-se

mais do que o horizonte que está além das disciplinas. Constitui a possibilidade de cada um colocar-se no lugar do outro, na busca da compreensão ampliada de sua disciplina. Neste sentido, a capacidade de transitar pelos diferentes campos é algo a ser buscado. (SUERTEGARAY, 2003. p.51 - sem grifos no original)

Nessa ótica, percebe-se o possível diálogo do tema agroecologia dentro do ensino de Geografia, pois

\begin{abstract}
A agroecologia fornece uma estrutura metodológica de trabalho para a compreensão mais profunda tanto da natureza dos agroecossistemas como dos princípios segundo os quais eles funcionam. Trata-se de uma nova abordagem que integra os princípios agronômicos, ecológicos e socioeconômicos à compreensão e avaliação do efeito das tecnologias sobre os sistemas agrícolas e à sociedade como um todo. Ela utiliza os agrossistemas como unidade de estudo, ultrapassando a visão unidimensional genética, agronomia, edafologia - incluindo dimensões ecológicas, sociais e culturais. (ALTIERI, 2004, p.18).
\end{abstract}

Ao analisar essa definição, observa-se que Altieri (2004) torna amplo o conceito de agroecologia, abordando o enfoque holístico e integrador do tema. Em relação ao ambiente, a sua compreensão é compatível com o conceito de Gliessman (2001), um autor precursor desse debate.

Todavia, em sua definição, Altieri (2004) comenta que a agroecologia trabalha relacionando a agricultura com os ecossistemas dentro de uma perspectiva holística, ou seja, envolvendo várias dimensões de análise, tomando percepção das relações existentes na natureza e das que envolvem a sociedade/natureza, utilizando todos esses recursos em prol do melhor funcionamento do sistema agroecológico. Entretanto, o foco maior do trabalho de Altieri (2004) é voltado à produção e toda a sua dinâmica ambiental.

Por sua vez, essas definições partem de uma mesma lógica de análise, mais voltadas para o meio físico, não aportadas sobre as relações humanas ou sociais envolvidas na mesma perspectiva agroecológica. Assim, contrapondo-se a esse foco de análise conceitual, Tedesco (2006) afirma que:

O conceito de agroecologia vem sendo muito utilizado ultimamente para identificar a sustentabilidade no meio agrícola e como referência às práticas agrícolas que buscam obter boa produtividade animal e vegetal, trabalho e moradias decentes, diversidade de alimentos, técnicas, métodos e experiências criadas e desenvolvidas utilizando técnicas não degradantes aos meios físico, atmosférico e biológico. (TEDESCO, 2006,p.24). 
Tedesco (2006) não cria um conceito sobre a agroecologia em seu trabalho. Ele é um cientista social e busca aportes teóricos e técnicos, utilizando autores que já citamos, Altieri (2004) e Gliessman (2001), para discutir o que denomina de práticas agroecológicas.

Sua pesquisa envolve a agroecologia e as mudanças nas relações sociais que ela propicia, abordando de forma relevante a questão da produção, e voltando sua atenção para as condições que as práticas agroecológicas trazem ao agricultor, tanto na renda, quanto na qualidade dos alimentos. Enfatiza, ainda, a importância da organização dos produtores camponeses em associações, principalmente os que produzem de forma agroecológica, para poderem fortalecer a classe, melhorar as condições de produção e venda e, consequentemente, a sua qualidade de vida, com uma nova prática de produção agrícola, uma nova forma de relação social e de estruturação econômica no campo. Assim, a agroecologia torna-se modificadora das dinâmicas socioespaciais existentes em uma determinada localização geográfica, principalmente se essa dinâmica espacial se apoia nas relações agrícolas como um importante aporte da produção ${ }^{6}$, sendo esse o caso de São Mateus do Sul - PR.

Esse tema pode ser trabalhado no Ensino Fundamental e Médio, onde todos os fatores envolvidos com a agricultura e, consequentemente, influenciados pelas práticas exercidas através da agroecologia, estão relacionados direta ou indiretamente com a realidade vivida pelos educandos, sejam estes moradores do meio urbano ou rural (CALLAI, 2002).

Além dessa relação, dentre os temas transversais ${ }^{7}$ instituídos pelos PCN's, os temas Meio Ambiente e Saúde são passíveis de serem trabalhados no nosso entendimento sob a ideia-tática de transitar. Numa aproximação e ao mesmo tempo num distanciamento aos PCN's (2001), no qual:

A análise dos problemas ambientais envolve questões políticas, históricas, econômicas, ecológicas, geográficas, enfim, envolve processos variados, portanto, não seria possível compreendê-los e explicá-los pelo olhar de uma única ciência. Como o objeto de estudo da Geografia, no entanto, refere-se às interações entre sociedade e natureza, um grande leque de temáticas de meio ambiente está necessariamente dentro do seu estudo. (PCN's, 2001, p.46 - sem grifos no original)

Considerando essa condição, a agroecologia, uma forma de produzir alimentos sem o uso de agroquímicos que afetam todo o ambiente, corresponde a uma mudança na maneira de

6 Leia-se produção em um sentido amplo, no contexto em que as dinâmicas são tracejadas na ordem do modo de produção total de vida, em um processo amplo e em um sentido inteiro de "produção de coisas (produtos) e de obras, de ideias e de ideologias, de consciência e de conhecimento, de ilusões e verdades" (LEFEBVRE, 2001, p.37).

7 Constituem-se em temas complexos, que as disciplinas trabalhadas isoladamente, em sala de aula, não têm condições de abordar, sendo necessário o envolvimento de inúmeras disciplinas (PCN's, 2001). 
o ser humano se relacionar com o ambiente, podendo gerar consequências positivas para as sociedades futuras. Esse aspecto pode ser trabalhado na Geografia, sem a necessidade de uma abordagem com outras disciplinas, embora reconheçamos que essa seria uma perspectiva ideal, sendo essa idealização entravada nas atuais condições do objeto da educação. O qual ousaríamos chamar de território da escola, ou seja, as múltiplas projeções espaciais da escola e ao mesmo tempo o movimento inverso, ambas relações imbuídas pelo poder. No tocante à Educação Ambiental, assim como os temas Meio Ambiente e Saúde, que devem ser trabalhados de forma integrada, pois

\begin{abstract}
As questões relacionadas ao tema saúde no Brasil são bastante complexas e muitas vezes contraditórias. (...) A análise dessas situações, tão presentes na vida da maioria dos alunos, é bastante favorável para que eles compreendam a relatividade das medidas estatísticas e das condições geográficas de acesso e de como elas podem ser manipuladas, em função de determinados interesses. Em Geografia, esse estudo dos dados pode ser cruzado com os temas relativos às desigualdades regionais, de distribuição de renda. Pode ser abordado ainda quando se tratar do tema cidade e campo, discutindo os modelos agrícolas e a fome (PCN's, 2001, p.47).
\end{abstract}

A agroecologia pode ser abordada de acordo com os PCN's, em se tratando do tema cidade e campo, ao discutir os modelos agrícolas e a fome, aos quais a questão da saúde está estreitamente relacionada, e também a questão da alimentação da população, que enfrenta diversos problemas devido ao consumo de produtos de baixa qualidade, tanto em relação à contaminação por produtos tóxicos, quanto à sua qualidade nutritiva. Sendo esse aspecto resultante dos processos agrícolas atuais, a produção de alimentos de forma orgânica, através da agroecologia, também se torna um elemento a ser trabalhado na Geografia dentro da sinalização do tema transversal e ao mesmo tempo enquanto uma provocação/abordagem possível sob o viés do trânsito.

Dessa maneira, por ser capaz de modificar as dinâmicas socioespaciais - através de suas relações com as instâncias econômicas, políticas e a qualidade de vida da população como um movimento social, permeado de inúmeras relações que apresentam características de resistência ao processo de globalização ${ }^{8}$, a agroecologia, além de ser um tema possível de ser trabalhado dentro do ensino da Geografia, pode também ser um elemento usado pelos professores para a explicação de alguns processos complexos estudados nessa ciência. Alguns exemplos seriam o estudo da relação entre o local e o global, da relação entre sociedade e

\footnotetext{
8 Quando falamos em resistência a globalização nos referimos como ela se apresenta, enquanto perversidade. Para pensarmos uma outra globalização, defendida por Santos (2004) como a construção de um novo universalismo.
} 
natureza e dos movimentos sociais, o que tornaria as aulas de Geografia mais dinâmicas e interessantes por possibilitarem a problematização das teorias através de suas negociações com as experiências espaciais vividas de forma direta, projetas e/ou ancoradas pelos educandos.

Merecendo destaque também uma contextualização histórica da problemática em tela. Apoiados em Ehlers (1996), realizamos

\begin{abstract}
um apanhado histórico do processo de concepção da agroecologia, devemos observar que algumas práticas consideradas alternativas existem há muitos anos e em diversas partes do mundo, entre elas, a Agricultura Biodinâmica, Agricultura Orgânica, Agricultura Biológica e a Agricultura Natural que surgiram em diversos lugares em torno de diferentes aspectos econômicos e sociais, entretanto, todos tinham como definição o termo alternativo (OKONOSKI; NABOZNY, 2009. p.68).
\end{abstract}

No entanto principalmente por consequência da industrialização do campo brasileiro tivemos esse processo "alternativo" extremamente freado. O que caracteriza a agroecologia como uma temática contemporânea. Sendo uma necessidade, principalmente na educação no espaço agrário (para o espaço agrário) a abordagem agroecológica, enquanto um posicionar-se ideológico (cosmovisão) do educador.

Esse destaque para uma postura ideológica do educador não corresponde de forma alguma a um partidarismo. Mas há uma forma de subversão educacional. Pois, embora estejamos destacando nesse texto propensões para a complexidade, para o trânsito, o híbrido, as relações, etc. Como respostas a uma face da educação moderna. Acrescentemos um outro ponto também contemporâneo, à globalização que fragmenta os territórios e os conhecimentos do mesmo (verticaliza e seleciona), entre outros aspectos. Assim, vale ressaltar que paradoxalmente a formação de sujeitos complexos, que aprendam a aprender, entre outros predicados angariados por instituições, como a Organização das Nações Unidas para a Educação, a Ciência e a Cultura (UNESCO), tem-se como pano de fundo as novas necessidades do mercado e da produção que não querem mais o sujeito especialista (disciplinado). Daí ideias como a formação continuada, trabalho em equipe (algumas bases do toyotismo), etc. Donde resulta a proposição de subversão? Justamente no entendimento do educador de trabalhar com esses novos conceitos numa lógica espacializante e contra os grupos hegemônicos que esperam (e que selecionaram poucos desses) pela formação de sujeitos complexos. 


\section{A AGROECOLOGIA EM SALA DE AULA: PRÁTICAS DE ESTÁGIO NO ENSINO FUNDAMENTAL E MÉDIO}

Dada a possibilidade da inserção do tema agroecologia como um tema de trânsito na disciplina de Geografia, de acordo com as sinalizações apresentados pelos PCN's do sistema educacional brasileiro, tema transversal integrado ao aspecto local e analisado dentro das relações, foram realizados dois trabalhos referentes aos processos agroecológicos e suas relações com o município de São Mateus do Sul - PR, os quais estavam integrados às práticas de estágio supervisionado.

Essas práticas tiveram como objetivo divulgar a agroecologia aos alunos, apresentá-la como um sistema de produção agrícola alternativa para a agricultura camponesa, demonstrando as relações existentes entre a agricultura e a qualidade de vida da população urbana e rural, a economia local e global, o ambiente e as relações sociais que o dinamizam e o transformam, de forma a enfocar todos esses processos da realidade do município de São Mateus do Sul - PR.

Salientamos que para a realização dessa prática de ensino, tanto no Ensino Fundamental quanto no Médio, pensou-se dentro de um mesmo movimento metodológico. Nesse processo, inúmeras etapas sucederam-se, vinculadas ao estágio supervisionado do curso e ao mesmo consorciado na demanda do Projeto Político Pedagógico do Curso que exigia a inclusão do tema pesquisado no Trabalho de Conclusão de Curso com a prática de ensino/estágio docente. Definido a temática (agroecologia) perpassamos inicialmente por uma pesquisa bibliográfica, focando a agroecologia e o ensino de Geografia.

Em uma segunda etapa, em contato com o Colégio, observamos as possibilidades de trabalho e os recursos didáticos disponíveis. O uso de vídeo, por exemplo, não foi cogitado, visto que deveria existir uma reserva prévia e ocuparia muito tempo no remanejamento dos aparelhos até a sala de aula, assim nos propulsemos a trabalhar em um sistema de discussões e diálogos entre educandos e o educador em estágio. Utilizando o quadro-negro, quando necessário, para fazer sistematizações dos respectivos debates. Essa metodologia foi utilizada com o intuito de deixá-los mais à vontade com o tema trabalhado e com isso propiciar a interação com a aula.

$\mathrm{Na}$ terceira etapa, em discussão com orientadores e observando a realidade de São Mateus do Sul - PR, onde a agricultura possui extrema importância na economia, os estabelecimentos rurais ocupam $52 \%$ da área do município e sua população rural equivale a mais de $42 \%$ do seu total. Uma parcela desses agricultores produz através da agroecologia 
organizados em uma Cooperativa de Familiares de Agricultores Agroecológicos - COFAECO e ligados a instituições de pesquisa e assistência a agricultura, como a AS-PTA e redes de compra e venda de produtos agroecológicos como a Rede Ecovida, tornou-se pertinente trabalhar com esse tema e realizando um trabalho prático junto a esses agricultores.

\section{ESTÁGIO NO ENSINO FUNDAMENTAL}

No Ensino Fundamental o trabalho foi realizado na $8^{\mathrm{a}}$ série A do Colégio Estadual Duque de Caxias, no período de maio a junho 2007.

As duas primeiras aulas foram destinadas a uma explanação geral dos principais problemas ambientais ocorrentes no mundo, como por exemplo, desmatamento e efeito estufa. Foram também citados de forma rápida os principais encontros realizados sob a tutela da Organização das Nações Unidas (ONU) para debater temáticas ambientais. Foi feito, ainda, um apanhado histórico da evolução dos estudos em educação ambiental e de sua amplitude em todo o mundo.

Os alunos interagiram durante essas aulas, citando alguns problemas e fazendo algumas perguntas. Nas outras aulas, com o auxílio das informações percepcionais dos educandos, esses problemas já discutidos foram transpostos para São Mateus do Sul- PR, ou seja, para a sua experiência cotidiana. De acordo com os depoimentos dos educandos, atestamos que alguns dos principais problemas ambientais ocorrentes no município eram causados pela prática da agricultura convencional, sendo que o uso de fertilizantes químicos e agrotóxicos era o principal fator poluidor das águas e do solo, além de causar sérios danos à saúde humana.

Em uma segunda experiência educativa (mais duas aulas) foram apresentadas aos alunos as práticas agroecológicas de cultivo como uma alternativa para mudança, dentro dessas práticas destacamos o aproveitamento de restos orgânicos na compostagem, a formulação de inseticidas através do uso de cinzas e sabão caseiro, plantios consorciados (pasto e reflorestamento/ árvores frutíferas e hortaliças), alguns tipos de compostos utilizados na adubação (todos orgânicos), tal como, foi exposta a ideia geral da produção ser integrada ao ecossistema que caracteriza a região, mostrando que a maioria das espécies cultivadas são nativas ou que foram adaptadas a anos ao ambiente local. Durante essas aulas, foi possível perceber a curiosidade e o interesse por esse assunto por grande parte dos educandos, muitos dos quais residentes no campo. 
Nas duas aulas seguintes foi realizada uma saída de campo com a turma para uma pequena propriedade agroecológica, localizada a cerca de $10 \mathrm{~km}$ de distância do Colégio. Essa saída de campo teve como principal objetivo mostrar como funciona o sistema agroecológico na prática, desde o preparo dos adubos, acondicionamento e proteção do solo, cultivos de espécies conjuntas, exemplos de como realizar o controle biológico, até uma comparação com a agricultura convencional, levando-se em conta temas como qualidade de vida, equilíbrio de biodiversidade, tipos de produção, etc.

Os aspectos sociais também foram expostos, aonde os produtores agroecológicos de São Mateus do Sul - PR participam de Associações e seus produtos são vendidos através de feiras, ou seja, diretamente ao consumidor evitando atravessadores. A relação de troca de produtos através do Circuito de redes Ecovida, onde participam municípios do Estado de São Paulo, Paraná, Santa Catarina e Rio Grande do Sul, e que propiciam uma maior diversificação de produtos nas feiras, visto que, por exemplo, espécies de frutas produzidas no litoral são vendidas em São Mateus do Sul -PR e grãos produzidos no interior paranaense são comercializados no litoral, todos produtos certificados pelo selo orgânico ECOCERT (OKONOSKI; NABOZNY, 2009).

Essa prática teve o auxílio do dono da propriedade rural visitada, Sr. Beto Volochen e do Secretário de Agricultura e Meio Ambiente de São Mateus do Sul, Sr. José Lemos Licheski, que também é produtor agroecológico; ambos nos acompanharam durante todo o tempo da visita.

Nas últimas duas aulas foi realizada uma avaliação em forma de "jogo". Essa prática foi escolhida por representar uma forma de avaliação didática e motivadora, aonde,

Todo jogo tem uma finalidade e constitui um desafio. Há uma performance a realizar, uma situação a vencer, um adversário a derrotar, uma barreira a ultrapassar, um esforço a executar para suplantar os limites. Ganha-se ou perde-se, procurandose ganhar. Neste sentido o jogo é altamente formador na medida em que exige a organização racional dos meios apropriados para atingir um fim também racionalmente estabelecido. (BARRA, et al,1996)

O processo metodológico dessa avaliação em formato de "jogo" iniciou-se na primeira aula, em que foi pedido aos educandos que formulassem perguntas sobre os temas de cada aula, no mínimo duas por aluno, as quais eram recolhidas, analisadas pelos professores, conferindo se eram cabíveis dentro dos temas expostos nos encontros e armazenadas para que fossem utilizadas nas últimas aulas como ferramentas do "jogo". 
Com a característica de "Passa ou Repassa", os educandos se dividiram em dois grupos, cada grupo nomeava um representante, responsável para enviar a resposta da pergunta ao professor, as perguntas eram sorteadas para o grupo da vez, dentro do tempo estabelecido, tendo o direito de responder ou passar ao outro grupo que, por sua vez, em um tempo menor, poderia responder ou repassar novamente para o primeiro grupo. As respostas possuíam pontuações diferenciadas, se respondidas no primeiro momento, no Passe ou no Repasse.

Essa foi uma tentativa de avaliar o aprendizado dos alunos, tanto na elaboração das perguntas, como nas respostas dadas pelo grupo formado durante o "jogo", tal como a capacidade de organização em grupo, trabalho em conjunto e boa comunicação. Além disso, foi uma opção para realizar uma revisão de todos os assuntos vistos durante o período do estágio, de uma forma mais dinâmica, sendo que as perguntas sorteadas foram elaboradas desde as primeiras aulas.

Nesse sentido, cria-se uma competição sadia, incentiva-se o raciocínio rápido e a organização em grupo, sendo uma atividade agradável. Diferentemente da competição em sociedade que apregoa para o individualismo. No âmbito avaliativo foca-se o que o educando sabe e os seus esforços para superação. Assim, demarcando também um posicionamento educacional no qual buscamos nos afastar e enfrentar as avaliações convencionais que frisam aquilo que o educando não sabe, expondo suas fragilidades. Não que essas não sejam necessárias de serem interpretadas pelos educadores, principalmente no sentido de re-orientar as suas próprias práticas (nesse caso dos dois professores, do estágio e em estágio permanentemente). O que não deixa de ser um jogo-inverso, contra o jogo-perverso (da educação e da sociedade).

Finalizando o processo, pensando na questão avaliativa, a prova (descritiva ou objetiva) foi rejeitada, visto que era um período muito pequeno de atuação e seria uma atividade desgastante para os alunos, tal como, para um trabalho mais elaborado caberia mais tempo. Assim, escolheu-se um tipo de "jogo" como um formato de avaliação mais pertinente a ocasião, o tempo e ao tema trabalhado.

\section{ESTÁGIO NO ENSINO MÉDIO}

O trabalho no Ensino Médio foi realizado na turma da $1^{\text {a }}$ série $\mathrm{B}$ do já citado colégio, durante o mês de junho de 2008. Diferentemente das práticas das aulas realizadas no Ensino Fundamental, que se basearam principalmente na relação da agroecologia com a conservação 
do ambiente, com os alunos do Ensino Médio as aulas foram pautadas principalmente na diferença entre as práticas agroecológicas e as práticas agrícolas convencionais, bem como na relação dessas práticas com a Geografia e com a economia e a cultura local. Foram elaborados assuntos mais complexos, tendo como princípio que os educandos pertenciam a uma faixa etária com maior amadurecimento cognitivo.

As duas primeiras aulas foram destinadas a uma explanação geral sobre os conceitos básicos relacionados com o tema, tais como agroecologia, agricultura camponesa e agricultura convencional. Falou-se também da interação do tema trabalhado com a Geografia. Entretanto, a discussão sobre a relação entre a agroecologia e a Geografia, juntamente com a interação destas com a realidade vivida pelos educandos se estendeu para mais uma das aulas, visto que o município de São Mateus do Sul - PR tem a agricultura como principal fonte econômica da população.

Após essa discussão mais abrangente, as duas aulas seguintes foram destinadas à especificação das duas práticas de cultivo trabalhadas no estágio. Foram definidos os padrões de produção, que incluem formas de adubação, uso de agrotóxicos, uso de maquinários agrícolas, tipos de cultivo e mão de obra utilizada em cada uma delas.

Ao especificarmos cada uma das produções, iniciamos uma comparação entre elas, diferenciando as práticas agroecológicas, baseadas em uso de adubos orgânicos e diversidade de produções, da agricultura convencional, baseada em produção de monoculturas, uso de agrotóxicos e fertilizantes químicos, discutindo também a viabilidade de ambas dentro da agricultura camponesa.

$\mathrm{Na}$ aula que sucedeu a da abordagem das diferentes produções, a sala foi dividida em dois grupos, sendo que um dos grupos apresentou pontos positivos e negativos da prática agroecológica e o outro apresentou aspectos negativos e positivos da agricultura convencional.

Os pontos citados pelos alunos foram escritos no quadro, para que fosse possível realizar uma prática. Os dados escritos eram relacionados entre si, mostrando aos educandos que todos os segmentos da sociedade estão interligados, por exemplo, uma determinada prática agrícola, devido aos meios utilizados para a produção, pode vir a afetar tanto o ambiente quanto a saúde da população urbana e rural e a economia das cidades, entre outras questões que possuem ligações diretas ou indiretas dentro do mesmo sistema.

Nessa mesma aula, foi realizado um exercício com os alunos, em que foi requerido que eles escrevessem no mínimo sete linhas, abordando a relação que cada um deles possui 
com a agricultura e com os agricultores, considerando para isso as discussões realizadas em sala de aula e a sua experiência espacial.

Nas últimas aulas, de acordo com o planejamento do trabalho, seria realizada uma saída de campo para uma propriedade familiar agroecológica e uma convencional, para que os alunos pudessem observar as diferenças nas práticas agrícolas, porém houve um problema em relação à disponibilidade de transporte para eles. Devido a isso, as últimas duas aulas foram realizadas em sala de aula. Foi feita uma revisão de todos os assuntos trabalhados nas aulas anteriores e os alunos elaboraram propostas quanto às posições "corretas" que devemos assumir para melhorar a situação socioespacial e ambiental atual, tendo como tema principal as questões agrícolas, porém, abordando muitos outros assuntos pertinentes, dentro de uma aproximação com a chamada Educação Ambiental. Para finalizar as atividades e também para avaliar o aprendizado dos alunos nesse período, eles escreveram um texto, abordando todos os assuntos trabalhados em sala.

\section{PENSANDO (O CONTÍNUO) EM DOIS ESTÁGIOS}

Analisando todo o processo de realização do estágio, cabe lembrar que a coleta de dados para a elaboração das aulas foi facilitada pela existência de inúmeros trabalhos realizados sobre a agroecologia no Brasil. As dificuldades surgiram, porém, na transposição didática dos dados coletados para o nível de entendimento dos alunos e na transposição de escalas para a realidade local.

Muitos desses estudos são feitos sobre um tipo específico de cultivo, o qual está adaptado a uma área distinta, sendo assim, era difícil debater com alunos de uma região subtropical, um tipo de produção agroecológica feita no Nordeste, por exemplo, sendo esse um dos principais motivos de ter sido realizada a saída de campo, ou seja, de ter sido debatido com os alunos como funciona uma propriedade agroecológica em seu contexto socioespacial.

Durante o trabalho foi possível perceber algumas dificuldades enfrentadas pelos professores das escolas públicas, principalmente ao tentar inserir aulas diferenciadas, dado o pouco tempo disponível em aula. Nesse caso específico, em que as aulas foram realizadas sempre no primeiro ou segundo horário do dia, foi possível perceber a perda sofrida na primeira aula devido ao atraso dos alunos; assim, foram mais bem aproveitados os dias em que foi possível lecionar durante duas aulas seguidas. 
Considerando que a agroecologia é um tema complexo, necessitando de tempo para ser trabalhado dentro da sua amplitude e importância, tendo como bom exemplo, seu ensino através da Pedagogia da Alternância em Casas Familiares Rurais em todo o Brasil, onde o ensino de agroecologia é integrado ao Ensino Médio, levando três anos de estudos para o educando formular conhecimentos adequados, práticos e teóricos do tema (BURGHGRAVE, 2006).

Porém, mesmo com esses empecilhos, o trabalho foi bem aproveitado pelos educandos. Na avaliação dos relatórios elaborados por eles, observou-se que esses conseguiram significar grande parte das informações trabalhadas nas aulas, mais especificamente, a diferenciação das formas de "culturas-agrícolas" e no que isso afeta suas próprias vidas. Isso também foi percebido durante as aulas referentes a esse assunto, pois os educandos citaram exemplos e participaram das discussões. Mais do que assimilar, reconstruíram o conteúdo a partir do cotidiano, o qual também passou a ser observado com um novo olhar pelos educandos.

Em relação às questões ligadas aos problemas da agricultura com todo um contexto social atual, dentro de aspectos como êxodo rural e dificuldades econômicas, foi visto que a dificuldade de eles entenderem como essa dinâmica social funciona foi maior, até mesmo por ser um assunto complicado e porque eles precisavam possuir uma bagagem de conhecimentos referente a cada aspecto citado, para, daí sim, conseguirem entender como o sistema funciona, integrado dentro de uma rede de relações, onde um fator pode afetar os outros, influenciando direta ou indiretamente a vida de todos. Assim, de maneira geral, dentre os trabalhos realizados em 2007, no Ensino Fundamental e em 2008 no Ensino Médio, buscou-se cooperar na formação de sujeitos críticos, dentro do contexto de suas realidades socioespaciais.

\section{CONSIDERAÇÕES FINAIS}

Considerando os aspectos gerais trabalhados, no Ensino Fundamental foram abordadas questões mais abrangentes dentro das relações ambientais, que pudessem fornecer a base necessária para o entendimento da importância das práticas da agroecologia na agricultura camponesa para a conservação do ambiente. Assim, assuntos como aquecimento global, desmatamento, formas de poluição, entre outros relacionados à questão ambiental, foram abordados, para que fosse possível expor aos alunos o que é a agroecologia, a agricultura camponesa, e correlacionar essas práticas com a realidade que eles constroem. 
No Ensino Médio, os assuntos abordados dentro do tema foram mais relacionados com a importância das práticas agroecológicas dentro do contexto social e econômico, onde essa alternativa pode evitar que famílias deixem o campo e se acumulem nas periferias de grandes cidades, entre outros fatores, devido aos altos custos da produção e à pressão dos grandes produtores para expandir seus latifúndios. Procurou-se, também, comparar as formas de produção convencionais e agroecológicas e apresentar os prós e os contras de ambas.

Todos os assuntos tratados foram relacionados com a realidade dos alunos, demonstrando que a permanência dos agricultores no campo é importante para todos, pois nos afeta direta ou indiretamente, através das dinâmicas econômicas locais e globais envolvidas e da disponibilidade de alimentos de qualidade, entre outros fatores que fazem da agricultura tema pertinente a ser trabalhado e discutido em todas as esferas de ensino.

Assim, a agroecologia se apresentou como um tema interessante para ser trabalhado dentro da Geografia do Ensino Fundamental e Médio, possuindo relação com os processos envolvidos nos estudos geográficos, tais como as relações sociedade e natureza, urbano e rural, os movimentos sociais e, as identidades territoriais, de lugar, de camponês, entre outras. Além disso, a agroecologia pode ser uma resposta criativa ao que é proposto sob o leque dos temas transversais pelos PCN's, entre eles, meio ambiente e saúde.

Ao compartilharmos essa experiência pedagógica longe de buscarmos trabalhar com a postura de um modelo, visamos provocar os educadores a buscar outros caminhos..., dentro daquilo que os mesmos observam nas espacialidades em que atuam como docentes.

Ela propicia, ainda, uma relação de ensino e aprendizagem em que o educando é um sujeito ativo, podendo analisar temas de seu contexto socioespacial que propiciarão uma melhor compreensão da relação dos aspectos geográficos trabalhados teoricamente e da relação dialógica que eles mantêm com sua experiência espacial.

Duas últimas questões finais. Perpassamos no texto a importância de observamos nos estágios de docência o envolvimento de duas escalas de relações. Educador e Educandos (supervisor), na universidade. Educadores (estagiários) e Educandos (mais supervisor e professor da escola), nas escolas. As relações se modificam e se complexificam na ordem numérica e na ordem dos focos. Fato que começamos o texto com um foco mais teórico (orientador), posteriormente nos enveredamos a uma descrição (reflexiva) na tentativa de demostrarmos como os pares se cruzam e, no cruzamento podem constituir estereoscopias para que possamos olharmos com/profundidades o(s) objeto (e objetivo $(s))$ da educação. 


\section{REFERÊNCIAS}

ALTIERI, M. A. Agroecologia: a dinâmica produtiva da agricultura sustentável. 4.ed. Porto Alegre: Editora da Universidade - UFRGS, 2004.

BARRA, V. M; CARNEIRO, S. M; LEME, S; OTA, S (Org.). Jogo: estratégia eficiente para a Educação Ambiental. Curitiba: Universidade Livre do Meio Ambiente. (Grupo de Estudos de Educação Ambiental. Subgrupo de Produção de Atividades Lúdicas), 1996 (não publicado). Disponível In:

www.pessoal.utfpr.edu.br/macloviasilva/.../jogo_estrat_educacaoambiental.pdf. Visitado em maio de 2007.

BERGER, P; LUCKMANN, T. A construção social da realidade. Petrópolis: Vozes, 1985.

BRASIL. Secretaria de Educação Fundamental. Parâmetros curriculares nacionais: Geografia/Secretaria de Educação Fundamental. Brasília: MEC/SEF, 2001.

BURGHGRAVE. T. D. A participação social: seus conceitos e a necessidade de uma pedagogia. In: Revista Formação por Alternância, Belo Horizonte (CEFFA’s), v. 3, nº 3, p. 16-34. Dez/ 2006.

CALLAI, H. C. Estudar o lugar para compreender o mundo. In: CASTROGIOVANNI, A. C.; CALLAI, H. C.; KAERCHER, N. A. (org). Ensino de Geografia: Práticas e textualizações no cotidiano. 2 ed. Porto Alegre: Editora Mediação, 2002.p. 83-134.

CAVALCANTI, L. S. Geografia e práticas de ensino. Goiânia: Editora Alternativa, 2002.

EHLERS, E. Agricultura Sustentável, origens e perspectivas de um novo paradigma. São Paulo: Livro da Terra, 1996.

FERREIRA, A.N de M; FERREIRA, A.P da S. O; MENDONÇA, M.R. A agroecologia no contexto escolar de Catalão (GO): Resultados de uma experiência. In: Anais XIX Encontro Nacional de Geografia Agrária, São Paulo, 2009, p.1-20.

GLIESSMAN, S. R. Agroecologia: processos ecológicos em agricultura sustentável. 2 ed. Porto Alegre: Editora da Universidade - UFRGS, 2001.

GOMES, P.C da C. Geografia e Modernidade. Rio de Janeiro: Bertrand Brasil, 1996.

LEFEBVRE, H. A cidade do capital. 2 ed. Rio de Janeiro: DP\&A editora, 2001.

LOWENTHAL, D. Geografia, Experiência e Imaginação: em direção a uma epistemologia geográfica. In: CHRISTOFOLETTI, A (org). Perspectivas da Geografia. São Paulo: DIFEL, 1982.p.103-141.

LATOUR, B. Jamais fomos modernos. Rio de Janeiro: Ed.34. 1992.

MORAES, A. C. R. Geografia: pequena história crítica, 19 ed. São Paulo: Editora Annablume, 2003. 
MORIN, E. Problemas de uma epistemologia complexa. In: MORIN, E (org). O Problema Epistemológico da Complexidade. Sintra - Portugal: Biblioteca Universitária, 1996. p. 1334.

OKONOSKI, T. H. R; NABOZNY, A. Agroecologia e dinâmica socioespacial local: uma alternativa para agricultores familiares de São Mateus do Sul - PR In: Terr@Plural, Ponta Grossa, v.3, n.1, p.67-87, jan./jul. 2009.

PEREIRA, M. F. R. A Geografia no pensamento filosófico. In: MERCATOR - Revista de Geografia da UFC. ano 05, número 10, p.31-37. 2006.

SAHR, C. L. L; SAHR, W-D. Territórios - faxinais - espaços. A problemática "espaço/território" na formação social brasileira. In: SAQUET, M. A; SPÓSITO, E. S. (org). Territórios e territorialidades: teorias, processos e conflitos. São Paulo: Expressão Popular, 2009. p.143-173.

SANTOS, M. Meio Técnico-científico-informacional e urbanização no Brasil. In: SANTOS, M. Técnica, Espaço e Tempo: globalização e meio técnico-científico-informacional, 2 ed. São Paulo: Editora Hucitec, 1996. p. 135-159.

Por uma outra globalização: Do pensamento único a consciência universal. 5 ed. São Paulo: Editora Record. 2004.

A Natureza do Espaço. 4 reipr. 4 ed. São Paulo: EDUSP, 2008.

SUERTEGARAY, D. M. A. Geografia e interdisciplinaridade. Espaço geográfico: interface natureza e sociedade. In: Geosul, Florianópolis, v.18, n.35, p. 43-53, jan./jun. 2003.

Geografia Física (?) Geografia Ambiental (?) ou Geografia e Ambiente (?). In: MENDONÇA, F. ;KOZEL; S. (org). Elementos de Epistemologia da Geografia Contemporânea. 2 ed. Curitiba:UFPR, 2004. p.111-120.

TEDESCO J. C. Agrodiversidade, agroecologia e agricultura familiar: velhas e novas faces de um processo de desenvolvimento na região de Passo Fundo - Pós-anos 90. Porto Alegre: Editora da Universidade de Passo Fundo, 2006. 